\title{
Roadway Support Optimization by Improved BP Neural Network and Numerical Simulation
}

\author{
Jun Wang, Yunliang Tan \\ Shandong University of Science and Technology \\ Qingdao 266590, China \\ caikuangwangjun@163.com
}

\begin{abstract}
Based on the analysis of the influence factors of the stability of roadway, we firstly collected the roadway support parameters of some roadways with good supporting effect and used them as the training samples of BP neural network. Then, we simulated the deformations of the forecasting samples and compared with the actual results to examine the accuracy of the supports scheme. At last, the optimal support scheme of No.3306 haulage roadway at Xinan Coal Mine, China was predicted by using improved BP neural network and it was verified by using the FLAC3D numerical simulation. The results showed that the model established by improved BP neural network has fast convergence, high accuracy and good stability ,and it could effectively predicted the roadway deformation and provided scientific basis for the supporting design of roadway
\end{abstract}

Keywords - Improved BP Neural Network; Numerical Simulation; Support Scheme; Optimal selection; Forecasting

\section{INTRODUCTION}

At present, the design of roadway support is mainly based on the theoretical calculation method and the engineering analogy method. The theoretical calculation method requires more parameters, and it is difficult to obtain accurate and reasonable value of many parameters in actual production, which can not meet the needs of production. The engineering analogy method is simple, but the influence of human factors and the lack of macro, comprehensive, and scientific basis results in high rate of the roadway repair and failure. Roadway is a complicated nonlinear system. Its support scheme selection and its influence factors, the surrounding rock deformation and its influence factors have a complex nonlinear relationship. BP neural network has high modeling ability, generalization ability and fault tolerance ability, which can describe the nonlinear relationship between the problem and its influencing factors. In coal mine production practice, the engineering technicians have accumulated many successful experiences in the selection of roadway support scheme, and BP neural network can obtain a large number of implicit knowledge, through the training of reasonable roadway support program, to achieve the rapid and accurate decision of the roadway support.

In recent years, many scholars have used BP neural network to carry out a wide and deep research on the design of roadway support, but they mainly used the neural network and the improved neural network to research the design of roadway support. Zhu et al. [1-3] who analyzed the influence factors of the stability of caving roadway, applied the improved BP neural network research on roadway support scheme optimization and prediction of roadway stability and found that the improved BP neural network can choose reasonable roadway support scheme as well as effective prediction of roadway deformation. Zhou et al. [4] utilized the nonlinear mapping function of dynamic BP network to realize the fully mechanized caving mining roadway bolting design, which found that the design results were close to the actual situation. Zhu et al. [5] found that the neural network has fault tolerance and memory ability to take association compensation and BP neural network is suitable for nonlinear classification problems. Wei et al. [6] utilized the BP neural network model, through the analysis of the geological condition and roadway support effect of Qian Yingzi mine and the main parameters which influence roadway support, establishing the samples space to train the network, and developing a visual interface design of supporting parameters software that was successfully applied in Qian Yingzi mine roadway support design. At present, numerical simulation method is widely used in roadway support design, while the application of BP neural network in roadway support design is a little. Further more, the combination of BP neural network and numerical simulation of roadway supporting design work is less.

In this paper, based on the analysis of the influence factors of the stability of roadway, we firstly collected the roadway support parameters of some roadways with good supporting effect and used them as the training samples of BP neural network. Then, we simulated the prediction samples to obtain the deformation of surrounding rock, and compared with the actual results to examine the accuracy of the support scheme. At last, the optimal support scheme of No.3306 haulage roadway at Xinan Coal Mine, China was predicted by using improved BP neural network and it was verified by using the FLAC3D numerical simulation.

\section{ANALYSIS OF INFLUENCE FACTORS OF ROADWAY STABILITY}

Strength of surrounding rock The strength of surrounding rock reflects the size of the surrounding rock's carrying capacity, and it plays an important role in the deformation and failure of the roadway. The smaller the rock strength is, the worse the stability of the roadway is. The uniaxial compressive strength of rock can reflect the mechanical and physical properties of surrounding rock. In this study, we choose the weighted average value of the uniaxial 
compressive strength of the roof and floor as the strength index of the surrounding rock.

Buried depth of roadway The original rock stress has great influence on the deformation of surrounding rock, which includes self weight stress and tectonic stress. The self weight stress is generally equal to $\lambda H .(\gamma$ is the average bulk density of the overlying strata; $H$ is the buried depth of the roadway)and raise with the increase of buried depth of the roadway. Therefore, the buried depth determines the self weight stress, which directly affects the deformation of the surrounding rock. A large number of field mine pressure observation shows that, with the increase of buried depth of the tunnel, the pressure and the surrounding rock displacement of the roadway raises.

Development degree of joint and fracture of surrounding rock Roadway surrounding rock containing bedding, joints,

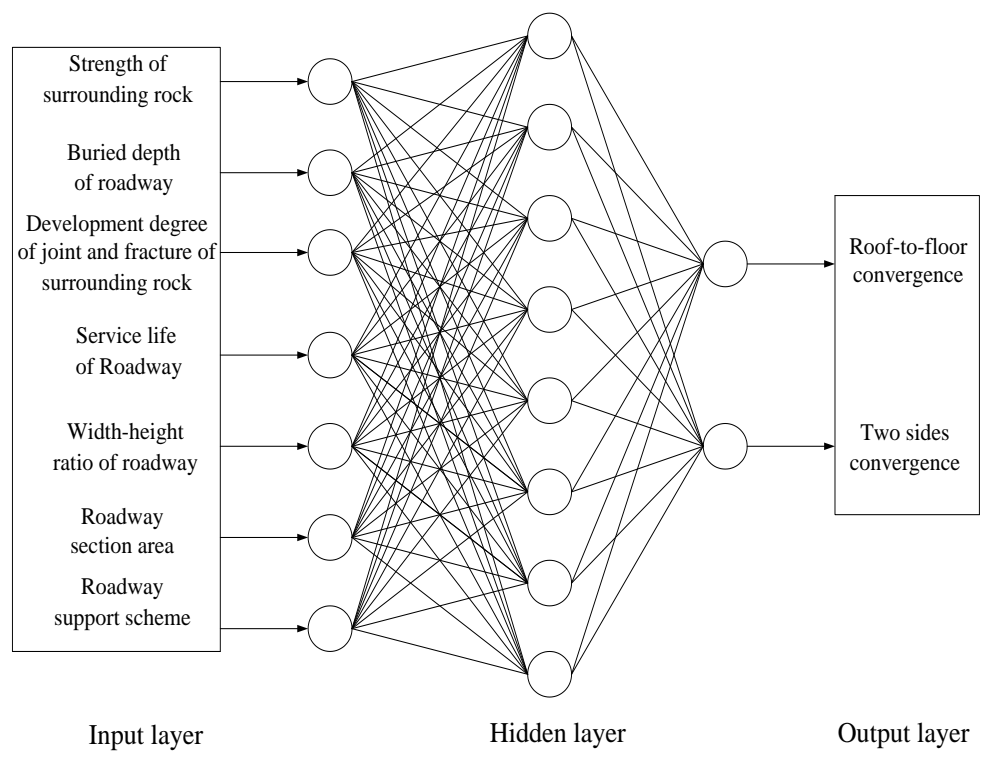

Fig.1. Neural network model

fissures and weak interlayer. These weak structural planes and surfaces significantly weakens the rock mass integrity and reduces the strength of rock, resulting in instability of rock of roadway and make it difficult to support. The development degree of the rock joint and fracture is a qualitative index, which is divided into 5 stages: clearly development, well development, middle development, a little development, little development.

Service life of roadway The influence of the time effect to the stability of roadway is very obvious. For example, many early digging roadway's deformation and damage are much more serious. So the tunnel of long service life required high support levels.

Width-height ratio of roadway The smaller width-height ratio of roadway is, the smaller roof hanging range is, which cause less damage to the roof of roadway in self weight stress and tectonic stress. The support strength can be appropriately reduced, but if this ratio is too small, the normal haulage will be affected. Therefore, this ratio needs a reasonable scope.
Roadway section area. The larger roadway section area is, the larger hanging roof range is, which makes it easier for the roof separation phenomenon or bending failure to occur. In addition, with the increase of the section area of the roadway, the destruction area of the roadway will be enlarged. The displacement of the surrounding rock will raise as well.

Roadway support scheme Roadway support is a process of mutual adjustment and interaction between support structure and surrounding rock structure. Its deformation and destruction are not only the deformation and failure of rock mass, but also the deformation and failure of the whole structure. If the performance of the support and the deformation and the failure of the surrounding rock are not compatible, it will cause serious damage to the support, such as the increase of surrounding rock displacement, the decrease of stability of the roadway.

In this paper, we choose 18 tunnels of 6 mines, and 12 kinds of support schemes. For a given roadway, the theoretical calculation method and engineering analogy method are initially utilized to select. Then the best support scheme is verified by the calculation results of neural network model and the numerical simulation.

\section{The Neural Network Model for OPTIMAL SUPPORT SCHEME}

\section{A. Improvement of BP Neural Network and Learning Algorithm}

BP neural network consists of input layer, one or more hidden layer and output layer, each layer can be composed of a number of nodes. Its learning algorithm can be obtained in literature [8]. The general BP algorithm has the problems of long training time, slow convergence rate and easy to form local minimum, etc. In order to overcome these shortcomings, the momentum factor [8] is introduced to optimize the BP

algorithm:

$$
\Delta w(n+1)=-\eta \frac{\partial E}{\partial w(n)}+\alpha \Delta w(n)
$$

where $n$ is the number of iterations; $\alpha$ is the momentum factor; $\eta$ is the learning rate; $\Delta w(n)$ is the adjustment of the weight between nodes; $\frac{\partial E}{\partial w(n)}$ is the error gradient.

The principle of momentum factor: if the gradient of two adjacent iteration points is consistent, momentum factor is introduced to make the adjustment of the weight increased, thus speeding up the convergence; if the gradient of two adjacent iteration point is opposite, momentum factor will reduce the adjustment of the weight, which avoids the error surface oscillation back and forth , and speeds up the convergence [8]. 
TABLE 1 The Qualitative Factors Which ARE QuANTIFIED

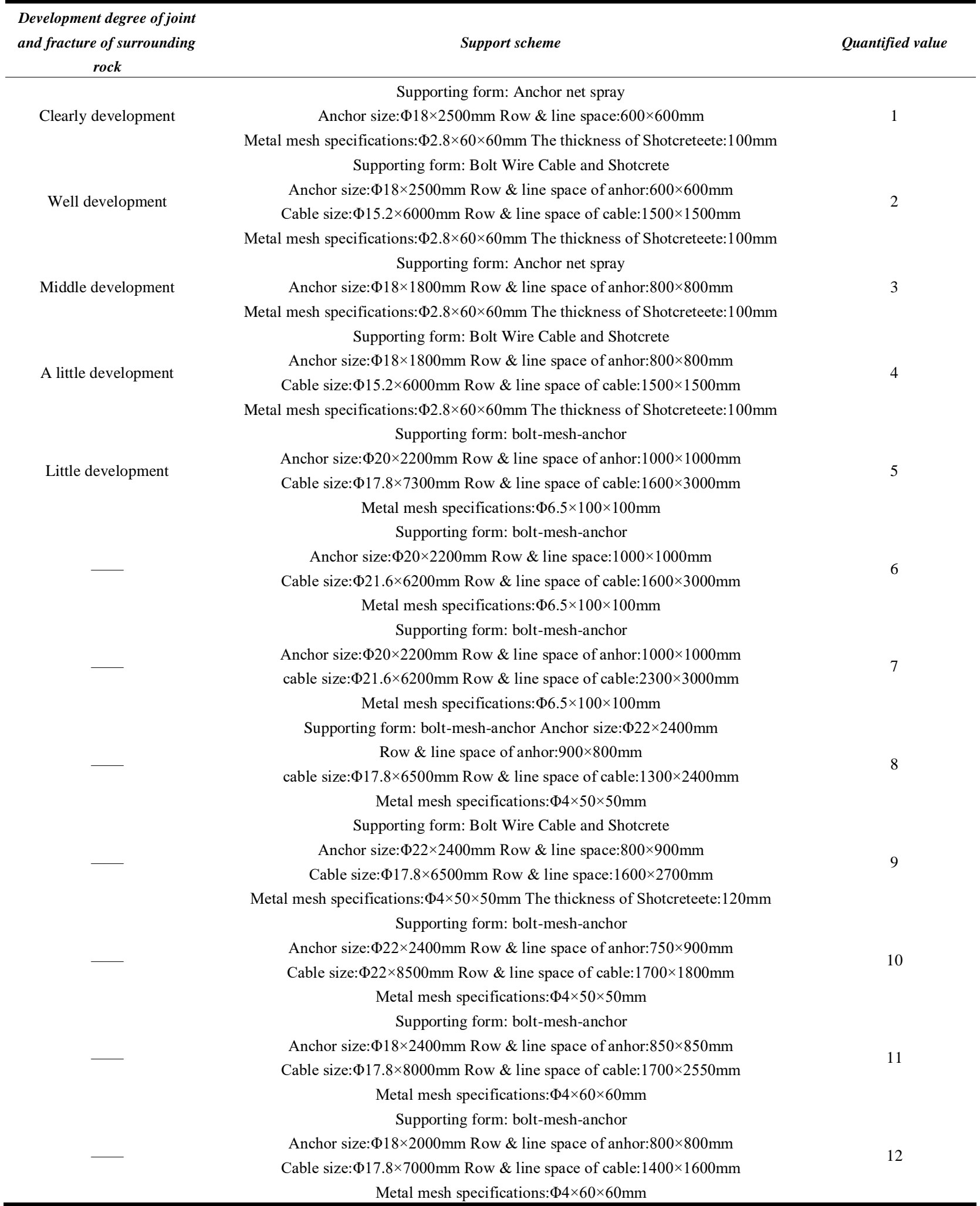

\section{B. The Determination of Network Structure And the Neural Network Model}

The 3 layers BP neural network is be adopted in the study. The node numbers of input layer are the seven factors affecting the stability of roadway. The node numbers of output layer are roadway's two main index which are usually served as measures of the stability roadway: roof-to-floor convergence and two sides convergence. The node numbers of 
hidden layer is 8 which can be obtained by formula (2). As a result, the network structure is determined to be 7-8-2, and the neural network model is shown in Figure 1.

$$
n=\sqrt{n_{i}+n_{o}}+a
$$

where $n$ is the node numbers of hidden layer; $n_{i}$ is the node numbers of input layer; $n_{o}$ is the node numbers of output layer; $a$ are constants and in the interval $(1,10)$.

18 roadways of 6 mines are selected as the study samples, which are shown in table 2 . The development degree of joint and fracture of surrounding rock and the support scheme are qualitative factors, so they should be quantified first and the quantified value are shown in Table 1 . The BP neural network computer program is developed based on the structure of BP neural network and the improved learning algorithm. 1 to 15 in Table 2 are selected as training samples to input to the BP neural network computer program, driven by MATLAB software that can learn and train the network. After 10000 steps, stable network structure and connection weights are gained.

TABLE 2 THE SAMPLES Of NEURAL NETWORK MODEL

\begin{tabular}{|c|c|c|c|c|c|c|c|c|c|}
\hline $\begin{array}{l}\text { Sample } \\
\text { number }\end{array}$ & $\begin{array}{c}\text { Strength of } \\
\text { surrounding } \\
\quad \text { rock } \\
/(M P a)\end{array}$ & $\begin{array}{l}\text { Buried } \\
\text { depth } \\
\text { of } \\
\text { roadw } \\
\text { ay } \\
/(m) \\
\end{array}$ & $\begin{array}{c}\text { Development } \\
\text { degree of } \\
\text { joint and } \\
\text { fracture of } \\
\text { surrounding } \\
\text { rock } \\
\end{array}$ & $\begin{array}{c}\text { Service } \\
\text { life of } \\
\text { Roadway } \\
/(a)\end{array}$ & $\begin{array}{l}\text { Width- } \\
\text { height } \\
\text { ratio of } \\
\text { roadw } \\
\text { ay }\end{array}$ & $\begin{array}{c}\text { Roadwa } \\
y \\
\text { section } \\
\text { area } \\
/(a)\end{array}$ & $\begin{array}{l}\text { Roadw } \\
\quad \text { ay } \\
\text { support } \\
\text { scheme } \\
\quad\left(\mathrm{m}^{2}\right)\end{array}$ & $\begin{array}{c}\text { Roof-to- } \\
\text { floor } \\
\text { convergenc } \\
e \\
/(\mathrm{mm})\end{array}$ & $\begin{array}{c}\text { Two sides } \\
\text { convergen } \\
\text { ce } /(\mathrm{mm})\end{array}$ \\
\hline 1 & 40.2 & 40 & 1 & 41 & 1.75 & 17.82 & 1 & 56 & 45 \\
\hline 2 & 42.1 & 170 & 1 & 41 & 1.75 & 17.82 & 2 & 98 & 76 \\
\hline 3 & 29.0 & 20 & 2 & 41 & 1.58 & 13.65 & 3 & 32 & 24 \\
\hline 4 & 18.6 & 62 & 4 & 41 & 1.53 & 11.45 & 3 & 43 & 29 \\
\hline 5 & 46.4 & 640 & 3 & 41 & 1.54 & 12.68 & 4 & 48 & 31 \\
\hline 6 & 69.8 & 615 & 3 & 1.1 & 1.30 & 20.80 & 5 & 40 & 53 \\
\hline 7 & 39.8 & 615 & 3 & 1.1 & 1.32 & 22.14 & 5 & 20 & 40 \\
\hline 8 & 40.4 & 642 & 2 & 2 & 1.38 & 22.00 & 6 & 526 & 359 \\
\hline 9 & 40.4 & 642 & 2 & 2 & 1.29 & 22.70 & 7 & 624 & 437 \\
\hline 10 & 34.9 & 615 & 3 & 1.6 & 1.43 & 21.84 & 5 & 546 & 368 \\
\hline 11 & 34.9 & 615 & 3 & 1.6 & 1.38 & 21.06 & 5 & 616 & 454 \\
\hline 12 & 21.4 & 1000 & 2 & 2 & 1.29 & 10.08 & 8 & 250 & 145 \\
\hline 13 & 21.4 & 1000 & 2 & 2 & 1.29 & 10.08 & 8 & 212 & 127 \\
\hline 14 & 52.8 & 980 & 1 & 55 & 1.62 & 18.24 & 9 & 63 & 38 \\
\hline 15 & 42.3 & 555 & 3 & 1.8 & 1.29 & 18.62 & 10 & 163 & 233 \\
\hline 16 & 32.3 & 227 & 3 & 1.3 & 1.62 & 10.92 & 11 & 346 & 273 \\
\hline 17 & 32.3 & 227 & 3 & 1.3 & 1.15 & 7.80 & 11 & 295 & 254 \\
\hline 18 & 37.8 & 586 & 2 & 1.5 & 1.43 & 11.20 & 12 & 449 & 386 \\
\hline
\end{tabular}

\section{Learning, Training and Testing of Neural Network}

16 to 18 in Table 2 which serve as the test samples are input to the neural network after learning and training. The forecasting results are shown in Table 3. From table 3, we can see that the forecasting results are in good agreement with the actual results, which shows that the optimized neural network model is of high accuracy and can meet the requirements of prediction.

TABLE 3 THE TEST RESUlTS

\begin{tabular}{ccccccc}
\hline & \multicolumn{3}{c}{ roof-to-floor convergence } & \multicolumn{3}{c}{ two sides convergence } \\
\cline { 2 - 7 } Sample number & $\begin{array}{c}\text { actual value } \\
/(\mathbf{m m})\end{array}$ & $\begin{array}{c}f o r e c a s t i n g \\
\text { value } \\
/(\mathbf{m m})\end{array}$ & $\begin{array}{c}\text { relative } \\
\text { error } \\
/(\%)\end{array}$ & $\begin{array}{c}\text { actual value } \\
/(\mathbf{m m})\end{array}$ & $\begin{array}{c}\text { forecastin } \\
\mathbf{g} \text { value } \\
/(\mathbf{m m})\end{array}$ & $\begin{array}{c}\text { relative } \\
\text { error } \\
/(\%)\end{array}$ \\
\hline 16 & 346 & 333 & 3.8 & 273 & 251 & 8.1 \\
17 & 295 & 322 & 9.2 & 254 & 239 & 5.9 \\
18 & 449 & 492 & 9.6 & 386 & 410 & 6.2 \\
\hline
\end{tabular}




\section{ENGINEERING APPLICATION AND NUMERICAL SIMULATION VERIFICATION}

\section{A. General Situation of the Engineering}

$3 \#$ coal is the main mining coal seam at Xinan Coal Mine, China . Immediate roof is sandy mudstone, with a average thickness of $5.5 \mathrm{~m}$. Immediate bottom is mudstone, with a average thickness of $2.5 \mathrm{~m}$. No.3306 haulage roadway is excavated in the coal seam along the floor, with $4.6 \mathrm{~m}$ in width and $4 \mathrm{~m}$ in height. This roadway is located in the soft rock. Because of the complexity of soft rock, it is difficult to maintain the roadway. Besides, the roadway section area of No.3306 haulage roadway section is large and it is close to 3304 working face gob. In the process of mining, the pressure of roadway roof and two sides increased, causing largely deformation of roadway surrounding rock, which increased the difficulty of roadway support. Therefore, it is an urgent problem to put forward reasonable and effective support scheme to control the deformation and failure of surrounding rock in this field.

\section{B. Forecasting Results and Discussion}

On the basis of theoretical analysis and calculation, No.11 support scheme is rudimentary choosed as the optimal scheme. The rest of the neural network input parameters: rock strength: 59.2MPa; roadway buried deep: $520 \mathrm{~m}$; development degree of joint and fracture of surrounding rock: 2 ; service life: $2 \mathrm{a}$; width-height ratio: 1.19 ; roadway section area: $17.71 \mathrm{~m}^{2}$. The deformation of surrounding rock in No.11 support scheme can be obtained after parameters are entered into the improved neutral network model. The roof-to-floor convergence and two sides convergence are $322 \mathrm{~mm}$ and $245 \mathrm{~mm}$. From the prediction results, we find that the roof-to-floor convergence and two sides convergence are smaller, which meet the requirements of the production field to the deformation of the surrounding rock surface.

But due to the number of learning samples is small, and the output results of MATLAB software simulation are not always consistent. The optimal support scheme obtained by BP neural network model exists certain error. So in order to check the optimal scheme is effective or not, the optimal support scheme is needed to take numerical simulation method for further verification.

\section{Numerical Simulation Verification}

\section{1) Model Building}

The FLAC3D numerical model is established according to the strata occurrence and geological data of No.3306 haulage roadway. The size of a model is $32.2 \mathrm{~m} \times 30 \mathrm{~m} \times 29 \mathrm{~m}$ (length $\times$ width $\times$ height). The model is defined by Mohr Coulomb law. Displacement boundary condition is applied on the boundaries of the model. X-velocity is set to be zero at both left and right boundaries. Y-velocity is set to zero at both front and back boundaries. X-velocity, y-velocity and $\mathrm{z}$ velocity are all set to be zero at bottom boundary. The top boundary is free. Buried depth of roadway is $-520 \mathrm{~m}$. Average unit weight of overlying strata is $25 \mathrm{kN} / \mathrm{m}^{3}$. So the model upper bounds are imposed to $12.5 \mathrm{MPa}$ vertical stress. The numerical model, vertical stress distribution and the physical and mechanical parameters of rock are shown in Figure 2,3 and Table 4.

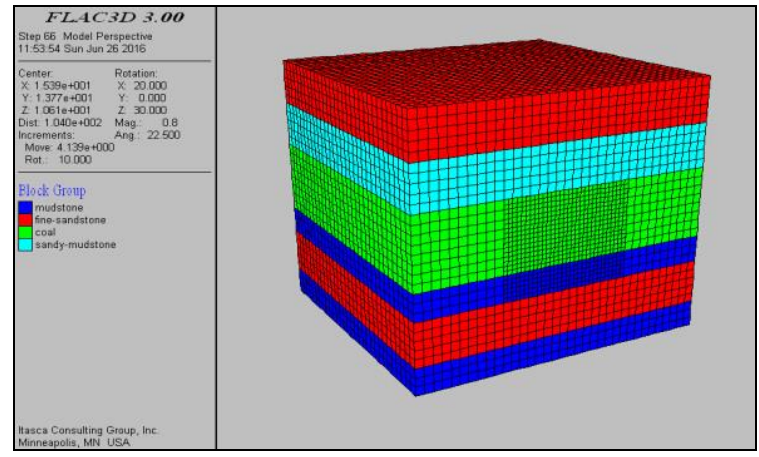

Fig.2. FLAC3D numerical model

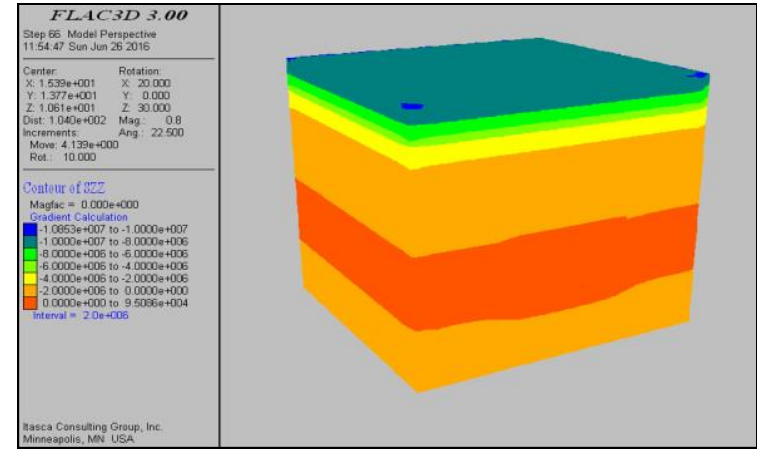

Fig.3. Vertical stress distribution

TABLE 4 The Physical And Mechanical Parameters OF RocK

\begin{tabular}{ccccccc}
\hline Lithology & $\begin{array}{c}\text { Bulk } \\
\text { modulus } \\
/(\mathbf{G P a})\end{array}$ & $\begin{array}{c}\text { Shear } \\
\text { modulus } \\
/(\mathbf{G P a})\end{array}$ & $\begin{array}{c}\text { Friction } \\
\text { angle } \\
/\left({ }^{\circ}\right)\end{array}$ & $\begin{array}{c}\text { Cohesion } \\
/(\mathrm{MPa})\end{array}$ & $\begin{array}{c}\text { Tensile } \\
\text { strength } \\
/(\mathbf{M P a})\end{array}$ & $\begin{array}{c}\text { Density } \\
/\left(\mathbf{k g} / \mathbf{m}^{3}\right)\end{array}$ \\
\hline $\begin{array}{c}\text { Mudstone } \\
\text { Fine }\end{array}$ & 1.21 & 0.66 & 31 & 2.16 & 1.65 & 2520 \\
$\begin{array}{c}\text { sandstone } \\
\text { Mudstone }\end{array}$ & 0.67 & 0.48 & 33 & 3.62 & 1.80 & 2570 \\
$\quad 0.58$ & 0.28 & 31 & 3.15 & 1.24 & 2520 \\
$\begin{array}{c}\text { Coal } \\
\text { seam }\end{array}$ & 0.52 & 0.25 & 28 & 3.24 & 1.28 & 1330 \\
$\begin{array}{c}\text { Sandy } \\
\text { mudstone } \\
\text { Fine }\end{array}$ & 0.76 & 0.33 & 30 & 3.05 & 1.54 & 2420 \\
sandstone & 1.34 & 0.74 & 34 & 4.36 & 3.14 & 2570 \\
\hline
\end{tabular}

2) Simulation Results and Discussion

The vertical displacement distribution and horizontal displacement distribution of the roadway are shown in Figure 2 and Figure 3. On the basis of Figure 4 and Figure 5, we can draw that the roof-to-floor convergence and two sides convergence of No.3306 haulage roadway are $143 \mathrm{~mm}$ and $153 \mathrm{~mm}$. The roadway surrounding rock deformation is very small, which can satisfy the requirement of the deformation of the surrounding rock in the tunnel when the support scheme 11 is adopted in No.3306 haulage roadway. Numerical simulation results is smaller than the neural network model of 
prediction results, which indicates that neural network model prediction results are partial conservative and safe. Creep of surrounding rock and working face advancing and other influence factors of roadway surrounding rock deformation are absent in the simulation process, so this deviation is allowed. Therefore, the simulation results can fully verify the reliability of the neural network model to the roadway support from the side. Combining the two methods improves the credibility of No.11 support scheme, so in the end ,it is determined the optimal support scheme.

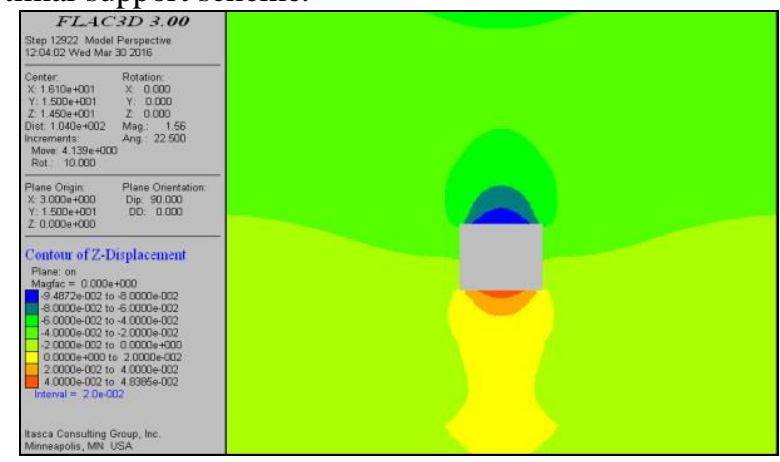

Fig.4. Vertical displacement distribution

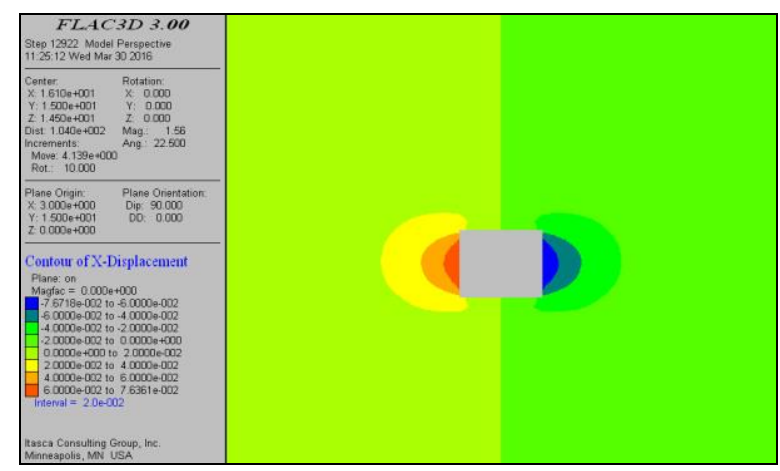

Fig.5. Horizontal displacement distribution

\section{CONCLUSION}

(1) There are seven main factors that affect the stability of roadway: strength of surrounding rock, buried depth of roadway, development degree of joint and fracture of surrounding rock, service life of roadway, width-height ratio of roadway, roadway section area and roadway support scheme.

(2) No.11 support scheme is rudimentary choosed as the optimal scheme. The roof-to-floor convergence and the two sides convergence are $322 \mathrm{~mm}$ and $245 \mathrm{~mm}$, forecasted by the improved BP neural network model. The roof-to-floor convergence and the two sides convergence are smaller, which meet the requirements of the production field to the deformation of the surrounding rock. Besides, the roof-to-floor convergence and the two sides convergence obtained by FLAC3D numerical simulation are $143 \mathrm{~mm}$ and $153 \mathrm{~mm}$, which is smaller than the forecasting results, verifying the reliability of the neural network model to the roadway support from the side. So No.11 support scheme is determined the optimal support scheme by combining the two methods in the end.
(3) The number of learning samples selected in this paper is inadequate. But the $\mathrm{BP}$ neural network has a strong adaptability and self organizing ability. With the increase of the number of learning samples that we are collecting, we will continue to improve the neural network model.

\section{ACKNOWLEDGMENT}

In this paper, this work is supported by National Natural Science Foundation of China (51274133, 51474137), Shandong Province Science and Technology Development Plan Item (2014GSF120002), and Tai'shan Scholar Engineering Construction Fund of Shandong Province of China.

\section{REFERENCES}

[1] ZHU Chuanqu, MIAO Xiexing, XIE Donghai.A model for optimization of support patterns of soft rock roadway based on neural network[J]. Chinese Journal of Geotechnical Engineering. 2001,23(6):708-710.

[2] ZHU Chuanqu, FENG Tao, SHI Shiliang.Application of neural network in optimal selection of bolt support patterns and deformation prediction of extraction roadway in fully-mechanized caving face $[\mathrm{J}]$. Journal of China Coal Science, 2005,30(3):322-326.

[3] ZHU Chuanqu, WANG Weijun, CHEN Liangpeng.Optimal selection of support patterns for caving roadway based on neural netwark[J]. Chinese Journal of Rock Mechanics and Engineering,2002,21(10):1483-1486.

[4] ZHOU Baosheng, ZHU Weishen, LI Shucai.Using neural network on bolting support desing of mining foadway for fully mechanized

[5] ZHU Zancheng, SONG Weidong, HE Minghua.et.al.The application of BP Network to the support of underground tunnel[J].Gold,2003,24(10):21-22.

[6] WEI Yancheng, WANG Renhe, ZHANG Jie.Application of Neural Network to Design of Mine Roadway Support Parameters Base on MATLAB[J].Coal Journal, 2010,(12):11-13

[7] KUANG Zhongxiang, SONG Weidong.Study on Application of Improved BP Neural Network in Support of Development Roadways[J]. Metal Mine, 2005,(3):19-21,37

[8] JIA Lihui, ZHANG Xiuru.Analysis and Improvements of BP Algorithm[M].Computer Technology and Development,2006,16(10):101-104.

[9] ZHANG Shi ke, RU Zhongliang, ZHAO Hongbo.Application of MATLAB Based on BP Neural Network in Bolt Supporting of Mining Roadway[J].Coal Mine Machinery, 2008,29(6):153-156.

[10] TAN Yunliang, WANG Yongjia.Neural network model of cluster anasysis for the classification indexes of gate[J]. Chinese Journal of Rock Mechanics and Engineering, 1995,14(2):139-144.

[11] TAN Yunliang, XIAO Yaxun, SUN Weifang.Self-adaptive wavelet neural network for recognizing and predicating outburst of coal and gas $[\mathrm{J}]$ Chinese Journal of Rock Mechanics and Engineering, 2007,26(1),3373-3377. 1995,14(2):139-144.

[12] ZHU Fusheng, ZHENG Yutian, TAN Yunliang.et.al.Optimal fuzzy identification of rock type in dateway with roof bolting support system[J].Journal of China Coal Science, 1997,22(3):265-269.

[13] TAN Yunliang, YU Feng-hai,NING Jianguo.Adaptability theory of roadside support in gob-side entry retainingand its supporting design[J].Journal of China Coal Science,2016,41(2);376-382.

[14] TAN Yunliang, WANG Yongjia.Method for determining plastic state of surrounding rocks of gate[J].Journal of Engineering Geology, 1996,4(2):6368. 